\title{
Pullout capacity of small ground anchors by direct cone penetration test methods and neural networks
}

\author{
Mohamed A. Shahin and Mark B. Jaksa
}

\begin{abstract}
Marquees are temporary light structures that are connected to the ground by small anchors that act in tension and are designed to resist uplift forces. Due to the temporary nature of these structures, little, if any, attention is given to the pullout capacity of the anchors used to secure them. Failures of such structures are not rare and have resulted in deaths and tens of thousands of dollars of damage. This paper reports on a series of 119 in situ anchor pullout tests conducted on rough mild steel anchors of various lengths, cross-sectional shapes, and areas. Comparison tests are carried out to investigate the impact of the factors affecting the pullout capacity of small anchors. Six methods that determine the axial pile capacity directly from cone penetration test (CPT) data are presented and used to calculate the pullout capacity of small ground anchors. The capacities obtained from these CPT-based methods are compared with predictions from a recently developed artificial neural network (ANN) model. The actual pullout loads are compared with predictions from the CPT and ANN methods, and statistical analyses are carried out to evaluate and rank their performance. The results indicate that the ANN-based method provides superior predictions of the pullout capacity of small ground anchors, whereas the Schmertmann method provides the best performance of the CPT-based techniques examined.
\end{abstract}

Key words: ground anchors, pullout capacity, cone penetration test, artificial neural networks.

Résumé : Les marquises sont des structures temporaires légères qui sont fixées au sol par de petits ancrages qui agissent en traction et sont conçus pour résister aux forces de soulèvement. À cause de la nature temporaire de ces structures, peu d'attention, si quelque attention, a été portée à la capacité d'arrachement des ancrages utilisés pour fixer en place ces structures. La rupture de telles structures n'est pas rare et a résulté en des pertes de vie et en des dizaines de milliers de dollars de dommages. Dans cet article, on a réalisé in situ une série de 119 essais d'arrachement d'ancrages en acier doux rugueux de différentes longueurs, différentes formes de la section en travers et de surfaces. On a comparé les résultats des essais pour étudier l'impact des facteurs affectant la capacité d'arrachement des petits ancrages. On présente six méthodes pour déterminer la capacité axiale d'un pieu directement à partir des données d'essais de pénétration (CPT) et elles sont utilisées pour calculer la capacité des petits ancrages dans le sol. On a comparé les capacités obtenues à partir de ces méthodes basées sur le CPT avec les prédictions obtenues au moyen d'un modèle de réseau de neurones artificiels (ANN) développé récemment. Les charges réelles d'arrachement sont comparées avec les prédictions des méthodes de CPT et d'ANN, et on a fait des analyses statistiques pour évaluer et classer leurs performances. Les résultats indiquent que la méthode basée sur l'ANN donne de meilleures prédictions de la capacité d'arrachement des petits ancrages dans le sol, alors que la méthode de Schmertman est la plus performante des techniques examinées basées sur le CPT.

Mots clés : ancrages dans le sol, capacité d'arrachement, essai de pénétration au cône, réseau de neurones artificiels.

[Traduit par la Rédaction]

\section{Introduction}

Marquees and other temporary light structures are almost exclusively connected to the ground by means of small anchors, often installed vertically, that resist uplift imposed by wind and other forces acting on the structure. The anchors resist the tensile forces from the structure by means of the shear resistance of the surrounding soil, hence providing structural stability. Traditionally, these anchors consist of steel rods, less than $1 \mathrm{~m}$ in length, that are driven into the ground, usually by means of a sledge hammer. Due to the short-term nature of temporary light structures, geotechnical investigations examining the pullout capacity of the anchors used to secure these structures are seldom, if ever, con-

Received 30 May 2005. Accepted 10 March 2006. Published on the NRC Research Press Web site at http://cgj.nrc.ca on 3 June 2006.

M.A. Shahin. School of Civil, Mining and Environmental Engineering, The University of Wollongong, Wollongong, NSW 2522, Australia.

M.B. Jaksa. ${ }^{1}$ School of Civil and Enviromental Engineering, The University of Adelaide, Adelaide, SA 5005, Australia.

${ }^{1}$ Corresponding author (e-mail: mjaksa@ civeng.adelaide.edu.au). 
Table 1. Generalized soil types and CPTs conducted at sites investigated.

\begin{tabular}{llc}
\hline Site & Soil type & No. of CPTs \\
\hline St. Peters River Park & Alluvial silt and sand & 11 \\
The University of Adelaide & Clay with some gravel & 10 \\
Seacliff Beach & Fine-grained sand & 3 \\
West Beach Playing Fields & Medium-grained sand & 3 \\
Newton Sports Ground & Highly plastic black clay & 3 \\
The University of South Australia & Red brown clay, dry, hard & 3 \\
\hline
\end{tabular}

ducted. Lau and Simmons (1986) stated that very little published information exists regarding the uplift capacity of small ground anchors. Das (1990) also indicated that the studies available to estimate the uplift capacity of anchor piles are limited. Failures of marquees and other light structures are not rare. Industry sources indicate that when marquees fail, they often need to be repaired or replaced, incurring costs of up to tens of thousands of dollars (I.R. Griggs, personal communication, 2002).

The purpose of this paper is to present a series of 119 in situ anchor pullout tests that were conducted at six different locations within Adelaide, South Australia, and to compare the results with predictions from six different methods of pile pullout capacity that use direct cone penetration test (CPT) data. In addition, the capacities obtained from these CPT-based methods are compared with predictions from an artificial neural network (ANN) model that was recently developed by Shahin and Jaksa (2005). A number of comparison tests are carried out to determine the influence of factors such as soil type, anchor diameter, embedment depth, installation technique, and natural variability on the pullout capacity of anchors. Statistical analyses, which compare the measured pullout loads with those obtained using the CPT methods and the ANN model, are carried out and used to evaluate and rank the performance of the pullout capacity prediction methods used. The sites selected for conducting the pullout load tests were chosen to incorporate a variety of soil types and geotechnical conditions. The study focuses on axial loading of rough anchors installed vertically, as these are most commonly used in practice. Three anchor types of different embedment depths, shapes, and cross-sectional areas are examined. Field and laboratory tests were carried out on soils at various sites to quantify the geotechnical properties and are described in the following section.

\section{Field and laboratory soil testing}

One consideration of the present study is to examine the influence of soil type on anchor pullout capacity. Six different locations were selected with the aid of the Soil association map of the Adelaide region (South Australian Department of Mines and Energy 1989). These include St. Peters River Park, The University of Adelaide (North Terrace Campus), Seacliff Beach, West Beach Playing Fields, Newton Sports Ground, and The University of South Australia (Levels Campus). To quantify the geotechnical soil properties at each site considered, a number of field and laboratory tests were carried out and are described as follows.

To obtain "undisturbed" soil samples for visual inspection and laboratory tests, a series of $70 \mathrm{~mm}$ push tubes were obtained from each site. Continuous soil samples, of approxi- mately $900 \mathrm{~mm}$ in depth, were also taken to correspond with the maximum anchor embedment depth. Several laboratory tests were performed to classify the soils, including sieve analyses, Atterberg limits, and moisture-content tests. The classification of the soil was carried out in accordance with the Unified Soil Classification System (USCS), and the results of the tests conducted were used to prepare borehole $\log$ s for each site. Details of the soil profiles at each site are given by Shahin and Jaksa (2003). The results of the tests yielded the general soil types summarized in Table 1.

To quantify the geotechnical properties relevant to the CPT methods used to determine the pullout capacity of ground anchors, a number of CPTs were performed at each site investigated. In most cases, three CPTs were performed within a $1 \mathrm{~m}$ radius of the anchor pullout tests. The CPT data were recorded at $10 \mathrm{~mm}$ intervals and involved measurement of cone tip resistance, $q_{\mathrm{c}}$, and sleeve friction, $f_{\mathrm{s}}$, along with the depth of the cone penetrometer. The sleeve friction values were shifted by $75 \mathrm{~mm}$ to correspond with the depths at which the data for the cone tip resistance are measured. This is necessary because the raw sleeve friction data obtained consist of values that are offset by $75 \mathrm{~mm}$ due to the physical layout of the apparatus, as required by the International Society of Soil Mechanics and Foundation Engineering (1989). Table 1 shows the number of CPTs conducted at each site investigated. In general, one to three CPTs were performed within $1 \mathrm{~m}$ of the location of the anchor. A typical example of three of the CPT measurements conducted at the University of South Australia site is shown in Fig. 1. It is evident from this figure that the measurements from the three CPTs are very similar, which is expected because the tests were performed within a $1 \mathrm{~m}$ radius. There are small differences, however, and the influence of this spatial variability is discussed later in the paper.

\section{Anchor field tests}

A total of 119 in situ pullout tests were conducted on mild steel small ground anchors with a surface typical of that used in practice. Three anchor types (i.e., circular, hexagonal, and star dropper) with different tip embedment depths (i.e., 400, 600, and $800 \mathrm{~mm}$ ) and cross-sectional areas were examined (Fig. 2; Table 2). These anchors were selected because they are representative of those most commonly used in the marquee industry. A description of the field tests conducted is given as follows.

To achieve consistent installation, the majority of the anchors were statically inserted into the ground to the required embedment depth, using a drilling rig hydraulic ram, at a constant rate of $20 \mathrm{~mm} / \mathrm{s}$. In practice, however, as marquee anchors are generally installed dynamically, by means of a 
Fig. 1. Typical example of CPTs and borelog conducted at the University of South Australia site.

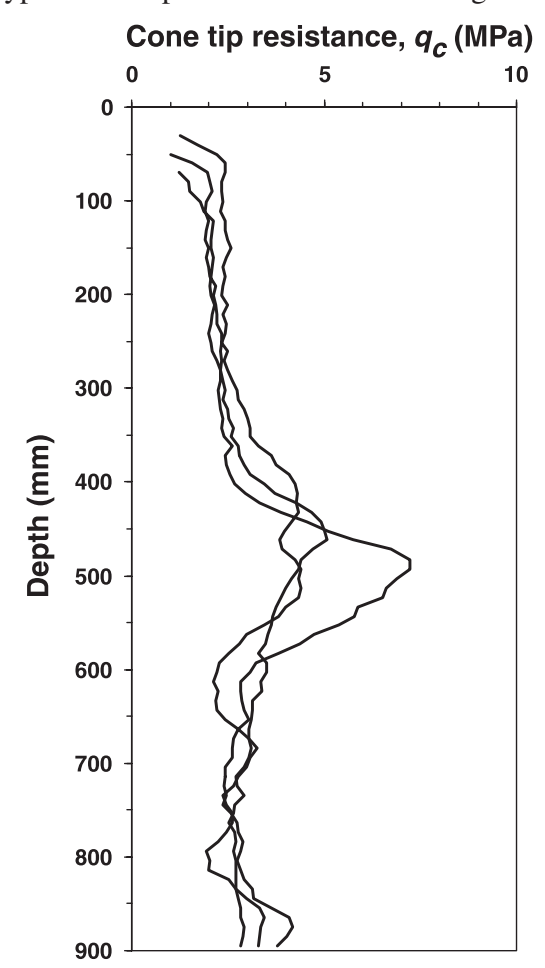

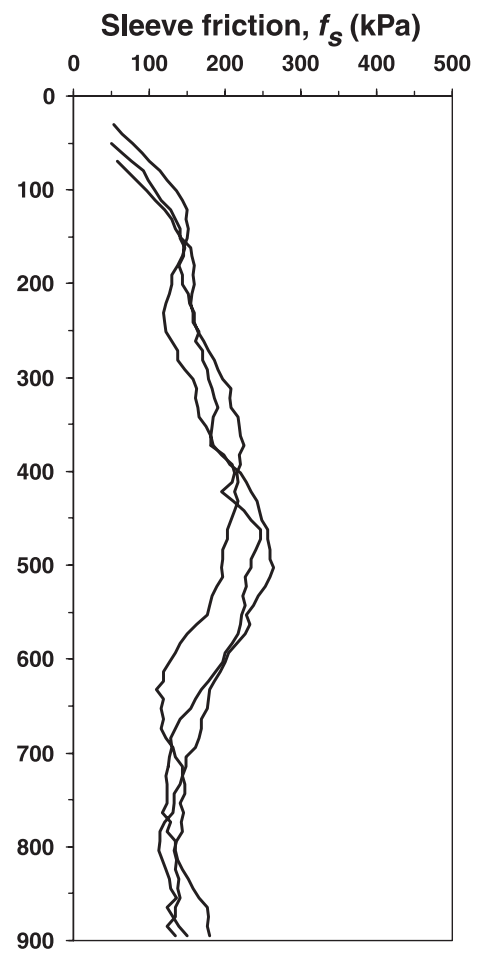

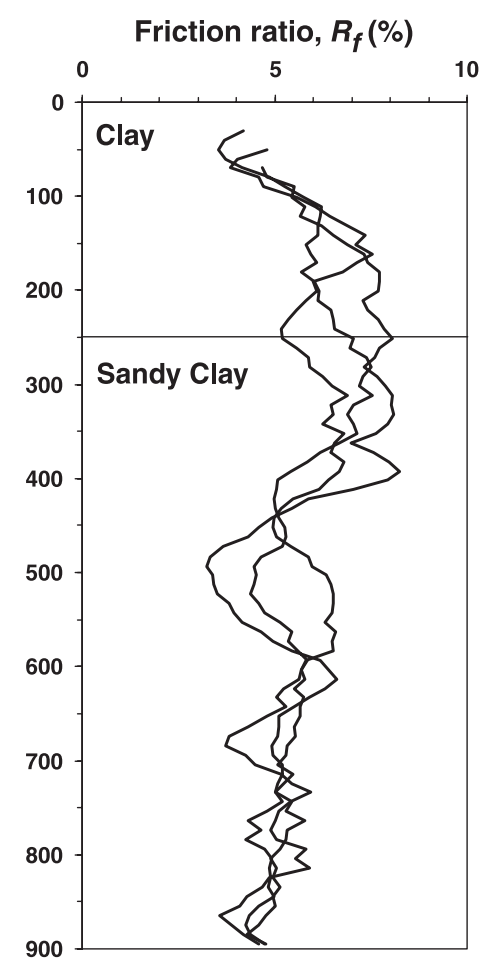

Fig. 2. Anchors used in pullout tests. From the left are star dropper (1350 $\mathrm{mm}$ in length), circular, and hexagonal anchors.

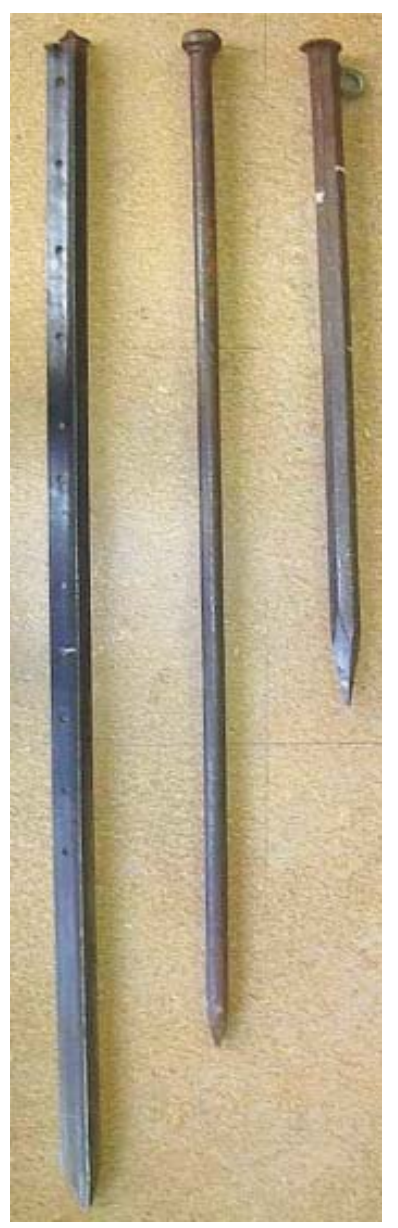

sledge hammer, some of the anchors were installed using this technique. The effect of the increase in pore-water pressure, as a result of dynamic installation, was not considered because it was beyond the scope of the study and the water table was several metres below the base of the installed anchors. The pullout tests were thus carried out a short time after installation, as is typical for such temporary ground anchors.

The pullout field tests were carried out using a mediumsized four-wheel-drive drilling rig (Fig. 3). The drilling rig hydraulic ram was used to withdraw the anchors vertically from the ground at a constant rate of $1 \mathrm{~mm} / \mathrm{s}$. A load cell was attached to the hydraulic ram by means of chains and shackles to allow measurement of the tensile load applied to the anchor during withdrawal. A yoke and pin adapter were attached to the anchor head to facilitate axial loading. A string potentiometer was attached to the anchor to measure vertical anchor displacement, $\delta$, during withdrawal. Load and displacement measurements were acquired using a computer data acquisition system at a sampling rate of $2 \mathrm{~Hz}$. For all pullout tests conducted, the peak anchor pullout load occurred within an anchor head displacement of $0.4 \delta / D_{\text {eq }}$ (or $20 \mathrm{~mm}$, where $D_{\text {eq }}$ is the equivalent anchor diameter = (anchor perimeter $) / \pi$ ), and most often it occurred within $0.1 \delta / D_{\text {eq }}$ (or $5 \mathrm{~mm}$ ). This is in contrast with the definition of pullout capacity given by Lau and Simmons (1986), who defined the pullout capacity as the load obtained at an anchor head displacement of $50 \mathrm{~mm}$. Consequently, it is concluded that anchor pullout capacity be defined as the peak load obtained during anchor withdrawal, as defined by Ghaly and Clemence (1998), provided that anchor head displacement is not excessive, e.g., less than $50 \mathrm{~mm}$, to limit structural distress. Details of the data obtained from the 119 tests are given by Shahin and Jaksa (2003) and summarized in Ta- 
Table 2. Characteristics of anchors used.

\begin{tabular}{lllllll}
\hline Anchor type & $\begin{array}{l}\text { Perimeter } \\
(\mathrm{mm})\end{array}$ & $\begin{array}{l}\text { Equivalent diameter } \\
(\mathrm{mm})^{a}\end{array}$ & $\begin{array}{l}\text { Area } \\
\left(\mathrm{mm}^{2}\right)\end{array}$ & $\begin{array}{l}\text { Length } \\
(\mathrm{mm})\end{array}$ & $\begin{array}{l}\text { Weight } \\
(\mathrm{kN})\end{array}$ & $\begin{array}{l}\text { Cross-sectional } \\
\text { shape }\end{array}$ \\
\hline Circular & 78.5 & 25.0 & 490.9 & 1160 & 0.045 \\
Hexagonal & 103.7 & 33.0 & 855.3 & 0.059 \\
Star dropper & 140.0 & 33.5 & 539.0 & 760 & 0.027 \\
\end{tabular}

Fig. 3. Schematic diagram of anchor testing equipment and data acquisition system.
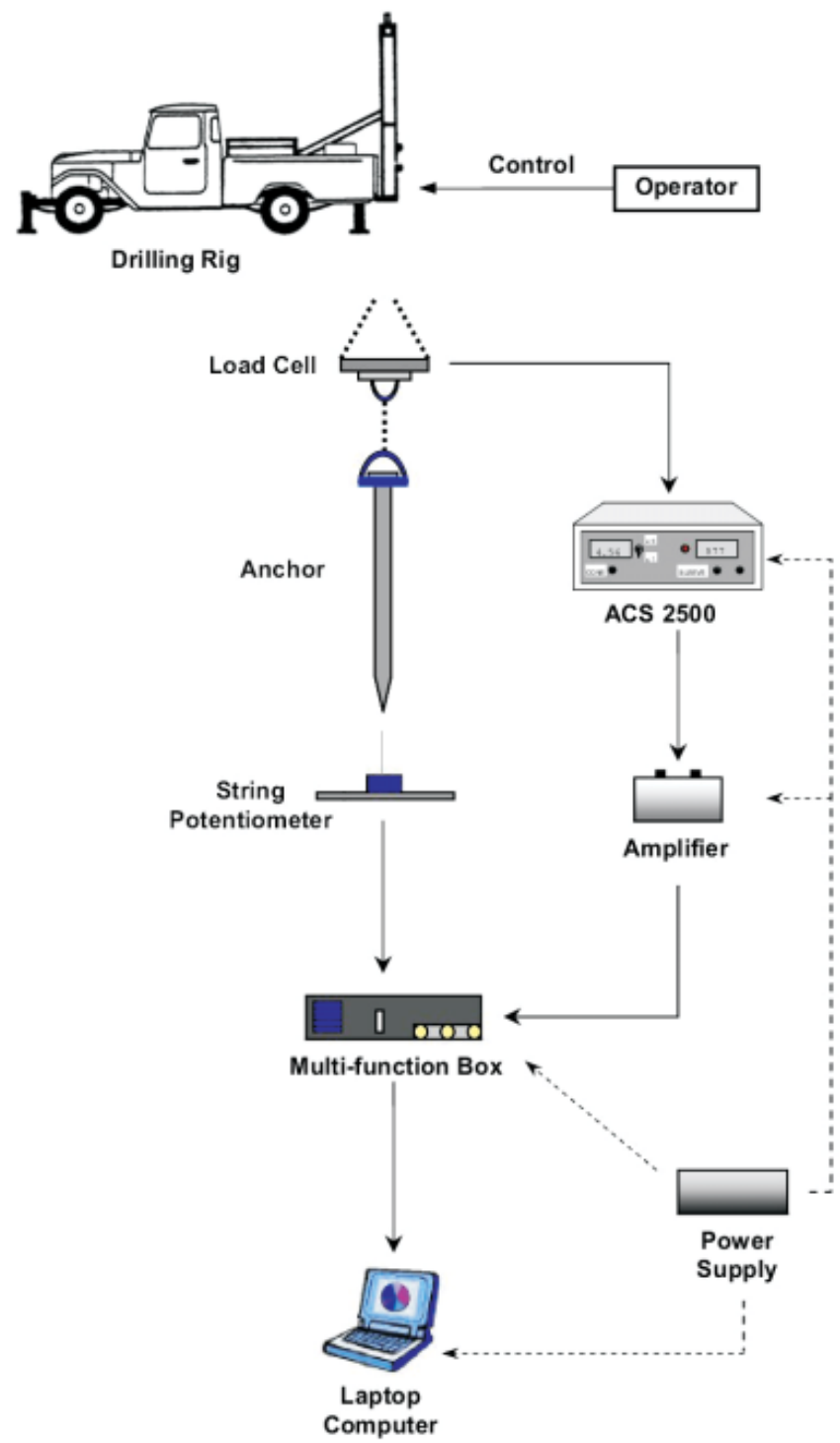

ble 3 . Included in the table are predicted pullout capacities, $Q_{\mathrm{p}}$, derived from the ANN model. These are discussed later in the paper.

\section{Overview of anchor test results}

The pullout capacity of small ground anchors is affected by several factors, including the type or cross-sectional shape (e.g., circular, hexagonal) of the anchor; anchor width (or diameter), embedment length, and surface roughness; the type of soil in which the anchor is embedded; and the method used to install the anchor (e.g., static push or dynamic) (Hanna et al. 1972; Lun 1985; Xanthakos 1991). The results of several pullout tests are examined in Fig. 4 in which the numbers adjacent to each plot refer to the pullout tests identified in Table 3. The ultimate pullout capacities, $Q_{\mathrm{u}}$, are normalized with respect to the measured sleeve friction, $\bar{f}_{\mathrm{s}}\left(\equiv f_{\text {ave }}\right)$, averaged along the anchor embedment depth, and the surface area, $A$, of the embedded anchor; and the displacements, $\delta$, are normalized relative to the equivalent anchor diameter, $D_{\text {eq }}$. Figure $4 a$ presents the results of 10 tests, where the equivalent anchor diameter, embedment depth, and soil and anchor type vary between tests. Each of the tests, however, involved anchors installed using the static method. Despite the fact that normalized results are presented, it is clear from Fig. $4 a$ that significant scatter remains. In addition, it is evident from Fig. 4 that the peak pullout load generally occurs within an anchor displacement of $0.4 \delta / D_{\text {eq }}$.

Figure $4 b$ presents the results of four tests performed in sand and clay soils using both the static and dynamic installation techniques. The tests were performed using circular anchors, $25 \mathrm{~mm}$ in diameter, and an embedment depth of $600 \mathrm{~mm}$. As expected, the pullout capacity of small ground anchors is greatly influenced by the installation method and, of course, the soil type. Figure $4 b$ shows that, for both the clayey and sandy sites, static installation produces higher pullout capacities than dynamic installation. This is not unexpected and is likely due to the fact that static installation causes less lateral disturbance of the adjacent soil than dynamic installation and thus provides greater shaft adhesion and higher pullout capacity. This is also in agreement with Lun (1985), who found that the adopted installation method influences pullout capacity.

Lastly, Fig. $4 c$ shows the results of three "identical" tests performed using circular anchors, $25 \mathrm{~mm}$ in diameter, and an embedment depth of $600 \mathrm{~mm}$ in sandy soil (average cone tip resistance $\bar{q}_{\mathrm{c}}=1.74 \mathrm{MPa}$, and average sleeve friction $\bar{f}_{\mathrm{s}}=$ $35.93 \mathrm{kPa}$ ), using the dynamic installation technique. Despite careful attention to detail and the anchors being located 
Table 3. Data from field pullout tests and ANN model predictions.

\begin{tabular}{|c|c|c|c|c|c|c|c|}
\hline Test No. & $D_{\text {eq }}(\mathrm{mm})$ & $L(\mathrm{~mm})$ & $\bar{q}_{\mathrm{c}}(\mathrm{MPa})$ & $\bar{f}_{\mathrm{s}}(\mathrm{kPa})$ & Installation technique $^{a}$ & $Q_{\mathrm{u}}(\mathrm{kN})$ & $Q_{\mathrm{p}}(\mathrm{kN})$ \\
\hline 1 & 25.0 & 800 & 3.55 & 26.01 & 2 & 1.11 & 1.52 \\
\hline 2 & 25.0 & 800 & 1.68 & 54.35 & 2 & 2.19 & 2.09 \\
\hline 3 & 25.0 & 600 & 1.65 & 52.10 & 1 & 2.47 & 2.08 \\
\hline 4 & 25.0 & 600 & 1.89 & 46.83 & 1 & 2.01 & 1.95 \\
\hline 5 & 33.0 & 400 & 2.28 & 179.71 & 2 & 1.76 & 2.02 \\
\hline 6 & 33.0 & 800 & 2.24 & 105.10 & 2 & 2.95 & 2.83 \\
\hline 7 & 33.5 & 600 & 1.89 & 46.83 & 1 & 2.08 & 2.10 \\
\hline 8 & 33.0 & 800 & 3.55 & 26.01 & 2 & 1.71 & 1.84 \\
\hline 9 & 25.0 & 400 & 1.05 & 55.68 & 1 & 1.16 & 1.55 \\
\hline 10 & 44.6 & 400 & 1.66 & 40.94 & 2 & 1.96 & 1.45 \\
\hline 11 & 25.0 & 600 & 2.67 & 13.99 & 2 & 0.35 & 0.82 \\
\hline 12 & 25.0 & 600 & 1.28 & 64.64 & 1 & 3.20 & 2.35 \\
\hline 13 & 44.6 & 600 & 1.89 & 46.83 & 1 & 1.90 & 2.09 \\
\hline 14 & 33.0 & 600 & 1.65 & 52.10 & 2 & 0.63 & 1.81 \\
\hline 15 & 25.0 & 600 & 1.65 & 52.10 & 2 & 1.52 & 1.50 \\
\hline 16 & 25.0 & 600 & 2.67 & 13.99 & 2 & 0.53 & 0.82 \\
\hline 17 & 25.0 & 600 & 1.89 & 46.83 & 1 & 1.76 & 1.95 \\
\hline 18 & 25.0 & 600 & 1.65 & 52.10 & 2 & 0.94 & 1.50 \\
\hline 19 & 44.6 & 600 & 1.65 & 52.10 & 2 & 1.73 & 2.31 \\
\hline 20 & 25.0 & 600 & 1.65 & 52.10 & 2 & 1.63 & 1.50 \\
\hline 21 & 25.0 & 600 & 2.20 & 87.93 & 2 & 2.18 & 1.87 \\
\hline 22 & 25.0 & 800 & 2.02 & 53.73 & 1 & 2.30 & 2.47 \\
\hline 23 & 25.0 & 600 & 1.74 & 35.93 & 1 & 2.03 & 1.63 \\
\hline 24 & 25.0 & 600 & 2.67 & 13.99 & 2 & 0.60 & 0.82 \\
\hline 25 & 44.6 & 600 & 1.28 & 64.64 & 1 & 2.49 & 2.53 \\
\hline 26 & 25.0 & 600 & 2.20 & 87.93 & 2 & 2.09 & 1.87 \\
\hline 27 & 44.6 & 600 & 1.74 & 35.93 & 2 & 2.95 & 1.93 \\
\hline 28 & 44.6 & 400 & 2.28 & 179.71 & 2 & 2.55 & 2.59 \\
\hline 29 & 25.0 & 600 & 1.28 & 64.64 & 1 & 2.15 & 2.35 \\
\hline 30 & 25.0 & 600 & 2.76 & 20.82 & 1 & 0.92 & 1.19 \\
\hline 31 & 33.0 & 400 & 0.95 & 12.22 & 2 & 0.29 & 0.66 \\
\hline 32 & 25.0 & 800 & 1.27 & 70.91 & 1 & 1.69 & 2.73 \\
\hline 33 & 33.0 & 600 & 2.20 & 87.93 & 2 & 2.39 & 2.24 \\
\hline 34 & 33.0 & 400 & 2.21 & 70.33 & 2 & 1.81 & 1.58 \\
\hline 35 & 25.0 & 600 & 2.76 & 20.82 & 1 & 1.19 & 1.19 \\
\hline 36 & 33.0 & 600 & 1.65 & 52.10 & 2 & 1.70 & 1.81 \\
\hline 37 & 25.0 & 600 & 2.76 & 20.82 & 2 & 0.73 & 0.94 \\
\hline 38 & 25.0 & 800 & 1.68 & 54.35 & 2 & 1.33 & 2.09 \\
\hline 39 & 44.6 & 400 & 1.05 & 55.68 & 1 & 1.34 & 2.14 \\
\hline 40 & 33.0 & 800 & 1.49 & 41.23 & 2 & 2.63 & 2.21 \\
\hline 41 & 25.0 & 600 & 1.74 & 35.93 & 2 & 1.73 & 1.23 \\
\hline 42 & 44.6 & 600 & 1.89 & 46.83 & 1 & 2.23 & 2.09 \\
\hline 43 & 25.0 & 400 & 1.05 & 55.68 & 1 & 1.06 & 1.55 \\
\hline 44 & 44.6 & 600 & 1.89 & 46.83 & 1 & 1.85 & 2.09 \\
\hline 45 & 25.0 & 400 & 1.63 & 44.46 & 2 & 1.36 & 1.14 \\
\hline 46 & 44.6 & 600 & 3.03 & 178.26 & 2 & 3.44 & 2.96 \\
\hline 47 & 25.0 & 600 & 2.67 & 13.99 & 2 & 0.48 & 0.82 \\
\hline 48 & 25.0 & 600 & 1.65 & 52.10 & 2 & 1.76 & 1.50 \\
\hline 49 & 25.0 & 400 & 1.66 & 40.94 & 2 & 1.25 & 1.09 \\
\hline 50 & 33.5 & 600 & 1.89 & 46.83 & 1 & 2.30 & 2.10 \\
\hline 51 & 25.0 & 400 & 2.21 & 70.33 & 2 & 1.37 & 1.46 \\
\hline 52 & 25.0 & 600 & 2.20 & 87.93 & 2 & 1.79 & 1.87 \\
\hline 53 & 25.0 & 600 & 2.76 & 20.82 & 2 & 0.94 & 0.94 \\
\hline 54 & 44.6 & 400 & 2.21 & 70.33 & 2 & 1.65 & 2.03 \\
\hline 55 & 25.0 & 600 & 1.89 & 46.83 & 1 & 1.87 & 1.95 \\
\hline 56 & 44.6 & 600 & 2.20 & 87.93 & 2 & 2.31 & 2.74 \\
\hline 57 & 25.0 & 800 & 1.27 & 70.91 & 1 & 2.48 & 2.73 \\
\hline
\end{tabular}


Table 3 (continued).

\begin{tabular}{|c|c|c|c|c|c|c|c|}
\hline Test No. & $D_{\text {eq }}(\mathrm{mm})$ & $L(\mathrm{~mm})$ & $\bar{q}_{\mathrm{c}}(\mathrm{MPa})$ & $\bar{f}_{\mathrm{s}}(\mathrm{kPa})$ & Installation technique $^{a}$ & $Q_{\mathrm{u}}(\mathrm{kN})$ & $Q_{\mathrm{p}}(\mathrm{kN})$ \\
\hline 58 & 33.5 & 600 & 1.28 & 64.64 & 1 & 2.79 & 2.51 \\
\hline 59 & 33.5 & 400 & 1.14 & 32.52 & 1 & 1.18 & 1.25 \\
\hline 60 & 25.0 & 600 & 2.02 & 53.73 & 1 & 3.02 & 2.12 \\
\hline 61 & 44.6 & 400 & 1.14 & 32.52 & 1 & 1.45 & 1.43 \\
\hline 62 & 25.0 & 600 & 3.03 & 178.26 & 1 & 2.09 & 2.94 \\
\hline 63 & 44.6 & 600 & 2.67 & 13.99 & 2 & 1.10 & 1.28 \\
\hline 64 & 25.0 & 600 & 2.67 & 13.99 & 1 & 0.90 & 1.02 \\
\hline 65 & 33.0 & 600 & 1.65 & 52.10 & 2 & 1.57 & 1.81 \\
\hline 66 & 25.0 & 600 & 3.03 & 178.26 & 2 & 2.19 & 2.14 \\
\hline 67 & 33.0 & 800 & 2.92 & 166.57 & 2 & 3.80 & 2.94 \\
\hline 68 & 25.0 & 600 & 2.67 & 13.99 & 1 & 0.87 & 1.02 \\
\hline 69 & 25.0 & 800 & 1.49 & 41.23 & 2 & 3.11 & 1.87 \\
\hline 70 & 25.0 & 600 & 2.76 & 20.82 & 2 & 0.61 & 0.94 \\
\hline 71 & 25.0 & 600 & 2.20 & 87.93 & 2 & 1.88 & 1.87 \\
\hline 72 & 33.5 & 600 & 1.89 & 46.83 & 1 & 2.39 & 2.10 \\
\hline 73 & 25.0 & 400 & 1.63 & 44.46 & 2 & 1.05 & 1.14 \\
\hline 74 & 44.6 & 400 & 2.28 & 179.71 & 2 & 2.39 & 2.59 \\
\hline 75 & 25.0 & 400 & 1.14 & 32.52 & 1 & 1.24 & 1.00 \\
\hline 76 & 44.6 & 600 & 1.28 & 64.64 & 1 & 2.29 & 2.53 \\
\hline 77 & 33.0 & 600 & 2.67 & 13.99 & 2 & 0.89 & 0.96 \\
\hline 78 & 33.5 & 600 & 1.28 & 64.64 & 1 & 3.11 & 2.51 \\
\hline 79 & 25.0 & 400 & 2.12 & 17.21 & 2 & 0.43 & 0.72 \\
\hline 80 & 25.0 & 600 & 2.20 & 87.93 & 2 & 1.98 & 1.87 \\
\hline 81 & 33.5 & 400 & 1.05 & 55.68 & 1 & 1.44 & 1.91 \\
\hline 82 & 33.0 & 800 & 1.68 & 54.35 & 2 & 2.22 & 2.45 \\
\hline 83 & 25.0 & 600 & 1.89 & 46.83 & 1 & 1.99 & 1.95 \\
\hline 84 & 44.6 & 400 & 1.63 & 44.46 & 2 & 0.78 & 1.53 \\
\hline 85 & 33.0 & 400 & 2.12 & 17.21 & 2 & 0.56 & 0.73 \\
\hline 86 & 25.0 & 600 & 1.65 & 52.10 & 2 & 2.42 & 1.50 \\
\hline 87 & 25.0 & 400 & 2.28 & 179.71 & 2 & 1.52 & 1.79 \\
\hline 88 & 25.0 & 600 & 1.65 & 52.10 & 1 & 1.70 & 2.08 \\
\hline 89 & 25.0 & 600 & 2.20 & 87.93 & 2 & 2.00 & 1.87 \\
\hline 90 & 33.0 & 400 & 1.63 & 44.46 & 2 & 1.44 & 1.20 \\
\hline 91 & 25.0 & 400 & 1.66 & 40.94 & 2 & 1.35 & 1.09 \\
\hline 92 & 25.0 & 600 & 1.89 & 46.83 & 1 & 2.16 & 1.95 \\
\hline 93 & 25.0 & 600 & 2.20 & 87.93 & 1 & 2.99 & 2.65 \\
\hline 94 & 33.5 & 600 & 1.89 & 46.83 & 1 & 1.90 & 2.10 \\
\hline 95 & 25.0 & 600 & 3.03 & 178.26 & 2 & 1.96 & 2.14 \\
\hline 96 & 44.6 & 600 & 1.65 & 52.10 & 2 & 1.90 & 2.31 \\
\hline 97 & 44.6 & 600 & 1.89 & 46.83 & 1 & 1.95 & 2.09 \\
\hline 98 & 44.6 & 400 & 0.95 & 13.99 & 2 & 0.63 & 0.83 \\
\hline 99 & 25.0 & 600 & 1.89 & 46.83 & 1 & 2.39 & 1.95 \\
\hline 100 & 33.0 & 600 & 2.76 & 20.82 & 2 & 0.96 & 1.11 \\
\hline 101 & 44.6 & 800 & 1.27 & 70.91 & 1 & 3.47 & 2.71 \\
\hline 102 & 33.5 & 600 & 1.89 & 46.83 & 1 & 2.24 & 2.10 \\
\hline 103 & 33.0 & 600 & 1.74 & 35.93 & 2 & 1.51 & 1.47 \\
\hline 104 & 44.6 & 600 & 2.76 & 20.82 & 2 & 1.10 & 1.48 \\
\hline 105 & 25.0 & 600 & 1.28 & 64.64 & 1 & 1.29 & 2.35 \\
\hline 106 & 25.0 & 600 & 1.28 & 64.64 & 1 & 2.09 & 2.35 \\
\hline 107 & 44.6 & 800 & 2.02 & 53.73 & 1 & 2.45 & 2.39 \\
\hline 108 & 25.0 & 600 & 1.65 & 52.10 & 2 & 2.00 & 1.50 \\
\hline 109 & 25.0 & 600 & 1.74 & 35.93 & 2 & 1.66 & 1.23 \\
\hline 110 & 25.0 & 600 & 1.74 & 35.93 & 2 & 1.54 & 1.23 \\
\hline 111 & 25.0 & 600 & 1.28 & 64.64 & 1 & 2.25 & 2.35 \\
\hline 112 & 25.0 & 600 & 1.65 & 52.10 & 1 & 0.90 & 2.08 \\
\hline 113 & 44.6 & 400 & 2.12 & 17.21 & 2 & 0.66 & 0.89 \\
\hline 114 & 25.0 & 800 & 1.27 & 70.91 & 1 & 3.06 & 2.73 \\
\hline 115 & 25.0 & 800 & 2.24 & 105.10 & 2 & 3.17 & 2.51 \\
\hline
\end{tabular}


Table 3 (concluded).

\begin{tabular}{llllclll}
\hline Test No. & $D_{\text {eq }}(\mathrm{mm})$ & $L(\mathrm{~mm})$ & $\bar{q}_{\mathrm{c}}(\mathrm{MPa})$ & $\bar{f}_{\mathrm{s}}(\mathrm{kPa})$ & Installation technique $^{a}$ & $Q_{\mathrm{u}}(\mathrm{kN})$ & $Q_{\mathrm{p}}(\mathrm{kN})$ \\
\hline 116 & 33.0 & 400 & 1.66 & 40.94 & 2 & 1.19 & 1.14 \\
117 & 25.0 & 400 & 0.95 & 12.22 & 2 & 0.35 & 0.66 \\
118 & 25.0 & 600 & 2.67 & 13.99 & 2 & 0.44 & 0.82 \\
119 & 25.0 & 600 & 1.89 & 46.83 & 1 & 2.00 & 1.95 \\
\hline
\end{tabular}

${ }^{a} 1$, static installation; 2 , dynamic installation.

Fig. 4. Factors affecting anchor pullout capacity and behavior: (a) effect of anchor type, equivalent diameter, embedment depth, and soil; $(b)$ effect of installation technique; $(c)$ effect of test variability.
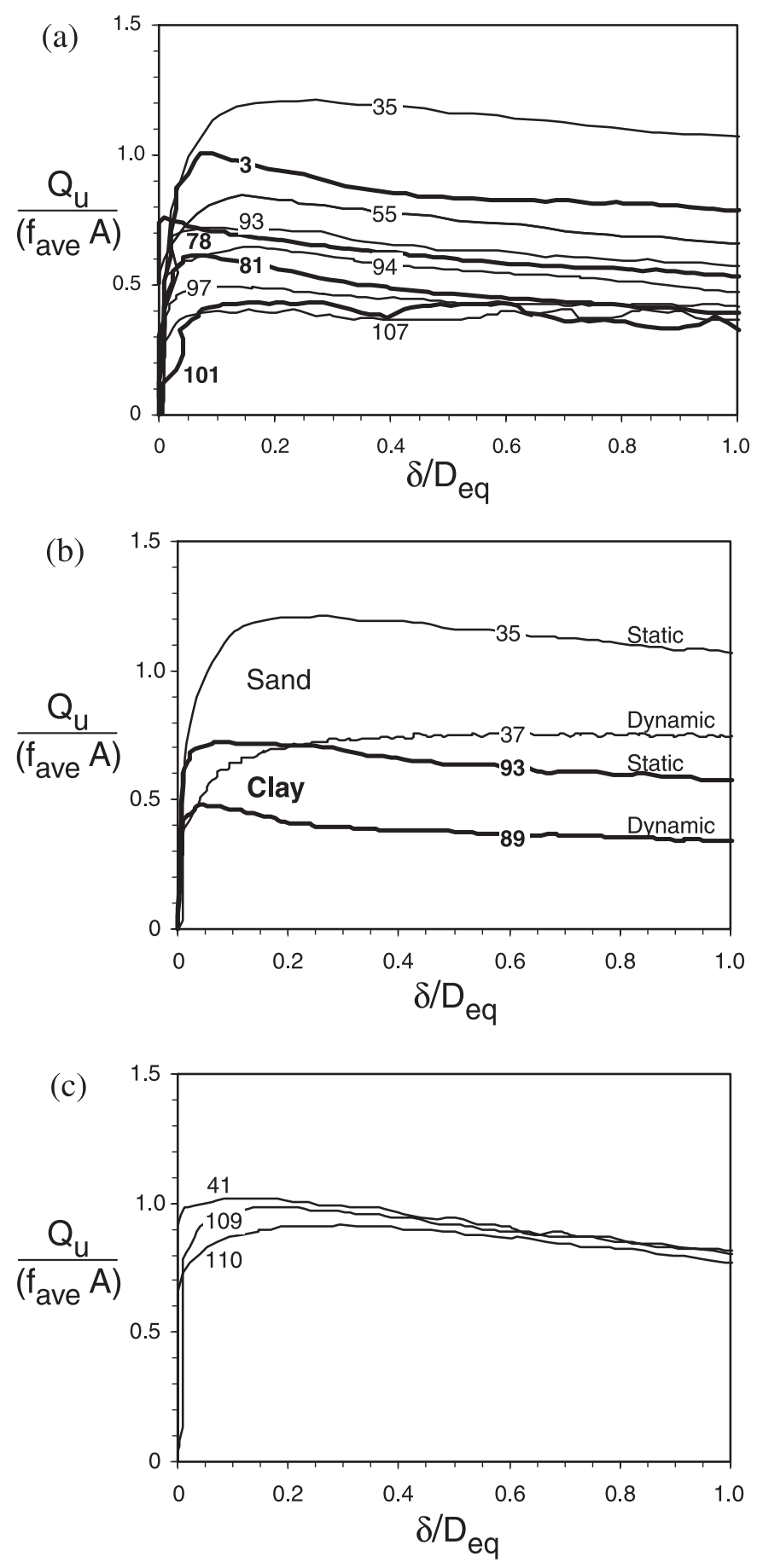

as near as practical to one another, it is evident from the results that natural test variability accounts for approximately $11 \%$ difference between the measured pullout capacities.

\section{CPT-based methods}

No theoretical methods are available that exclusively estimate the pullout capacity of small ground anchors. Since such anchors are essentially micropiles, it seems appropriate to adopt methods that have been developed to estimate the axial capacity of single piles, as the underlying physics are the same for both piles and small ground anchors. The ultimate pullout capacity, $Q_{\mathrm{u}}$, of an anchor can then be given by the following relationship:

$$
\text { [1] } Q_{\mathrm{u}}=Q_{\mathrm{b}}+Q_{\mathrm{s}}+W
$$

where $Q_{\mathrm{b}}$ is the base resistance, $Q_{\mathrm{s}}$ is the skin friction along the embedded shaft of the anchor, and $W$ is the weight of the anchor. For anchors subjected to pullout loads, $Q_{\mathrm{b}}$ and $W$ are usually negligible and hence can be ignored without significant loss of accuracy. As a consequence, $Q_{\mathrm{u}}$ is given by the following equation:

$$
Q_{\mathrm{u}}=Q_{\mathrm{s}}=f_{\mathrm{ave}} C_{\mathrm{p}} L
$$

where $f_{\text {ave }}$ is the average unit skin friction over the embedded depth of the anchor, $C_{\mathrm{p}}$ is the perimeter of the anchor cross section, and $L$ is the embedded length of the anchor. Several methods are available in the literature for calculating $f_{\text {ave }}$ based on CPT measurements. In the present work, the applicability of the following six different CPT-based methods is assessed in relation to the anchor field testing data: Aoki and De Alencar (1975), Penpile (Clisby et al. 1978), Schmertmann (1978), De Ruiter and Beringen (1979), LCPC (Bustamante and Gianeselli 1982), and Tumay and Fakhroo (1982). Details of the methods used to determine $f_{\text {ave }}$ are given in Table 4. The predicted anchor pullout loads are then compared with the corresponding measured pullout loads. Predictions from an ANN model recently developed by Shahin and Jaksa (2005) are also calculated and compared with the corresponding measured pullout loads. Statistical analyses that evaluate and rank the performance of the CPT and ANN methods are carried out and their results are discussed.

\section{Artificial neural network model}

As mentioned previously, an ANN model for the prediction of pullout capacity of small ground anchors is examined in this study. The ANN model was developed by Shahin and Jaksa (2005) and uses feed-forward multilayer perceptrons (MLPs) that were trained with the back-propagation algorithm (Rumelhart et al. 1986). The model has five inputs 
Table 4. Summary of CPT-based methods for predicting average unit skin friction.

\begin{tabular}{|c|c|}
\hline Method & $f_{\text {ave }}$ \\
\hline Aoki and De Alencar 1975 & $\begin{array}{l}f_{\text {ave }}=\bar{q}_{\mathrm{c}} \alpha_{1} / F_{2} \leq 120 \mathrm{kPa} \text {, where } \alpha_{1} \text { is a factor depending on soil type and } F_{2} \text { is a factor } \\
\text { depending on pile type }\end{array}$ \\
\hline Penpile (Clisby et al. 1978) & $f_{\text {ave }}=\bar{f}_{\mathrm{s}} /\left(1.5+14.47 \bar{f}_{\mathrm{s}}\right)$, with $f_{\text {ave }}$ and $\bar{f}_{\mathrm{s}}$ in $\mathrm{MPa}$ \\
\hline Schmertmann 1978 & $\begin{array}{l}\text { For clay, } f_{\mathrm{ave}}=k_{\mathrm{c}} \overline{\mathrm{f}}_{\mathrm{s}} \leq 120 \mathrm{kPa} \text {, where } k_{\mathrm{c}} \text { is a factor depending on pile shape and mate- } \\
\text { rial, cone type, and embedment ratio; for sand, } f_{\mathrm{ave}}=\frac{k_{\mathrm{s}}}{L}\left[\sum_{l=0}^{8 d}\left(\frac{l}{8 d}\right) \bar{f}_{\mathrm{s}} \Delta l+\sum_{l=8 d}^{L} \bar{f}_{\mathrm{s}} \Delta l\right]\end{array}$ \\
\hline De Ruiter and Beringen 1979 & $\begin{array}{l}\text { For clay, } f_{\mathrm{ave}}=\alpha \bar{q}_{\mathrm{c}} / N_{\mathrm{k}} \leq 120 \mathrm{kPa} \text {, where } \alpha \text { is a factor depending on clay type and } N_{\mathrm{k}} \text { is } \\
\text { a dimensionless factor ranging from } 15 \text { to } 20 \text {; for sand, } f_{\text {ave }}=\min \left\{\begin{array}{l}\bar{f}_{\mathrm{s}} \\
\bar{q}_{\mathrm{c}} / 400 \\
120 \mathrm{kPa}\end{array}\right.\end{array}$ \\
\hline Tumay and Fakhroo 1982 & $f_{\text {ave }}=m \bar{f}_{\mathrm{s}} \leq 72 \mathrm{kPa}$, where $m=0.5+9.5 \exp \left(-0.09 \bar{f}_{\mathrm{s}}\right)$ \\
\hline
\end{tabular}

Note: $\bar{q}_{\mathrm{c}}$ and $\bar{f}_{\mathrm{s}}$ are the cone tip resistance and sleeve friction, respectively, averaged over the embedded length of the anchor.

representing the anchor equivalent diameter, $D_{\text {eq }}(=$ (anchor perimeter) $/ \pi$ ); embedment depth, $L$; average cone tip resistance, $\bar{q}_{\mathrm{c}}$, along the embedment depth; average sleeve friction, $\bar{f}_{\mathrm{s}}$, along the embedment depth; and installation technique, given the abbreviated term InsTech, which was assigned a value of 1 for static installation and 2 for dynamic installation. The single model output was the ultimate pullout capacity, $Q_{\mathrm{u}}$. To obtain the most parsimonious and reliable ANN model, Shahin and Jaksa (2005) trained several neural networks with a different number of input variables, and a model with four inputs (i.e., $D_{\text {eq }}, L, \bar{f}_{\mathrm{s}}$, and InsTech) was found to be the best. The data used in the development of the ANN model and predictions of the pullout capacity, $Q_{\mathrm{p}}$, are included in Table 3 . Details of the ANN model development are beyond the scope of this paper and are given by Shahin and Jaksa (2005). To facilitate the use of the developed ANN model, Shahin and Jaksa translated the model into a relatively simple equation suitable for hand calculation, as follows:

$$
\begin{aligned}
Q_{\mathrm{p}}=0.29+3.5 /[1 & +\exp (1.74 \\
& \left.\left.+2.23 \tanh H_{1}-0.94 \tanh H_{2}\right)\right]
\end{aligned}
$$

where, for static installation (InsTech $=1.0)$,

$$
H_{1}=0.27+10^{-3}\left[7.2 D_{\text {eq }}-0.3 L-18 \bar{f}_{\mathrm{s}}\right]
$$

and

$$
H_{2}=-3.5+10^{-3}\left[70 D_{\text {eq }}+3.7 L+2.1 \bar{f}_{\mathrm{s}}\right]
$$

Alternatively, for dynamic installation $($ InsTech $=2.0)$,

$$
H_{1}=-0.04+10^{-3}\left[7.2 D_{\text {eq }}-0.3 L-18 \bar{f}_{\mathrm{s}}\right]
$$

and

$$
H_{2}=-4.74+10^{-3}\left[70 D_{\text {eq }}+3.7 L+2.1 \bar{f}_{\mathrm{s}}\right]
$$

where $Q_{\mathrm{p}}$ is the predicted pullout capacity $(\mathrm{kN}), D_{\text {eq }}$ is the equivalent anchor diameter $(\mathrm{mm}), L$ is the anchor embedment depth $(\mathrm{mm}), \bar{f}_{\mathrm{s}}$ is the average sleeve friction along the embedment depth (kPa), and $H_{1}$ and $H_{2}$ are temporary intermediate parameters.

\section{Assessment of CPT-based methods and the ANN model}

To evaluate and rank the CPT-based methods and the ANN model used in this study, the rank index (RI) proposed by Abu-Farsakh and Titi (2004) is used, as given by the following:

[8] $\mathrm{RI}=R_{1}+R_{2}+R_{3}+R_{4}$

The rank criteria used (i.e., $R_{1}, R_{2}, R_{3}$, and $R_{4}$ ) are described in detail by Abu-Farsakh and Titi (2004) and are summarized in the discussion that follows. Optimal performance of a pullout prediction method is indicated by a low value of RI. For each of the pullout capacity prediction methods used in the present work, the aforementioned rank criteria are determined and their results are given in Table 5.

The first criterion $\left(R_{1}\right)$ is determined by carrying out a regression analysis to obtain the best-fit line of $Q_{\mathrm{p}} / Q_{\mathrm{u}}$ of the available 119 anchor tests for each pullout capacity prediction method, and the relationship of the best-fit line of $Q_{\text {fit }} / Q_{\mathrm{u}}$ and the corresponding coefficient of correlation, $r$, are calculated. Based on this criterion, better performance is indicated by the prediction method that has both the ratio $Q_{\text {fit }} / Q_{\mathrm{u}}$ and $r$ closer to unity. The results of this criterion are shown in Table 5 for each of the prediction methods used. It can be seen that the ANN model of Shahin and Jaksa (2005) is given an $R_{1}$ value of 1 and thus ranks first. With this method, $Q_{\mathrm{fit}} / Q_{\mathrm{u}}=0.96$ with $r=0.83$, which implies that, according to the first criterion, the ANN method tends to underpredict the measured pullout capacity by an average of $4 \%$. It can also be seen that the method of De Ruiter and Beringen (1979) performs the worst. According to the first 


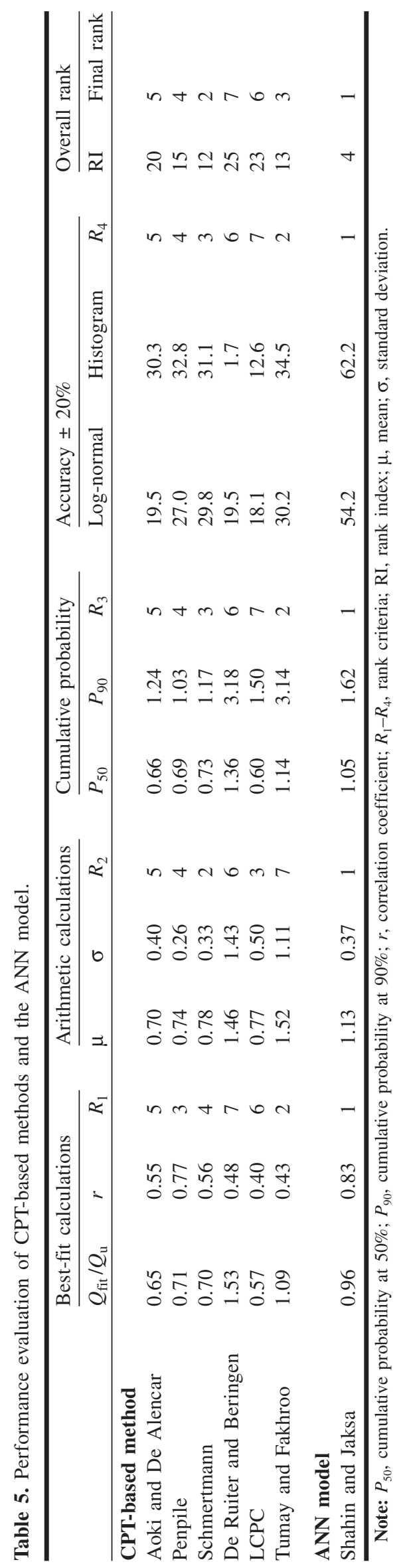

criterion, the De Ruiter and Beringen method tends to overpredict the measured pullout capacity by an average of $53 \%$, as it has $Q_{\mathrm{fit}} / Q_{\mathrm{u}}=1.53$ with $r=0.48$. It can also be seen that the Aoki and De Alencar, Penpile, Schmertmann, and LCPC pullout capacity prediction methods tend to underpredict the measured pullout capacity by average values of $35 \%, 29 \%, 30 \%$, and $43 \%$, respectively, whereas the Tumay and Fakhroo method tends to overpredict the measured pullout capacity by an average of $9 \%$.

The second criterion $\left(R_{2}\right)$ is obtained by calculating the arithmetic mean value, $\mu$, and the corresponding standard deviation, $\sigma$, of $Q_{\mathrm{p}} / Q_{\mathrm{u}}$ of the 119 anchor tests for each of the prediction methods used. Based on this criterion, optimal performance is obtained when $\mu\left(Q_{\mathrm{p}} / Q_{\mathrm{u}}\right)$ approaches unity with $\sigma\left(Q_{\mathrm{p}} / Q_{\mathrm{u}}\right)$ approaching zero. The results of this criterion are given in Table 5 for each of the prediction methods used. Again, it can be seen that the ANN model ranks first, with $\mu=1.13$ and $\sigma=0.37$, which means that, according to the second criterion, the ANN method tends to overpredict the measured pullout capacity by an average of $13 \%$. On the other hand, the Tumay and Fakhroo method ranks last, with $\mu=1.52$ and $\sigma=1.11$, which suggests that, according to the second criterion, this method tends to overpredict the measured pullout capacity by an average of $52 \%$. It can also be seen that four of the remaining methods (i.e., Aoki and De Alencar, Penpile, Schmertmann, and LCPC) tend to underpredict the measured pullout capacity by average values of $30 \%, 26 \%, 22 \%$, and $23 \%$, respectively, whereas the De Ruiter and Beringen method tends to overpredict the measured pullout capacity by an average of $46 \%$.

The third criterion $\left(R_{3}\right)$ is determined by sorting, in ascending order $(1,2,3, \ldots, i, \ldots, n)$, the ratios of $Q_{\mathrm{p}} / Q_{\mathrm{u}}$ of the 119 anchor tests for each of the pullout capacity prediction methods used against the cumulative probability $(P)$, which is calculated as follows (Long and Wysockey 1999):

$$
P=i /(n+1)
$$

where $i$ is the order number given for the considered ratio, and $n$ is the number of anchors. The $50 \%$ and $90 \%$ cumulative probabilities (i.e., $P_{50}$ and $P_{90}$ ) of $Q_{\mathrm{p}} / Q_{\mathrm{u}}$ are then obtained and used to measure the tendency of the prediction methods used to overpredict or underpredict the measured pullout capacity. Based on this criterion, optimal performance is indicated by values of $P_{50}$ and $P_{90}$ approaching unity. The results of this criterion for each of the methods used are given in Table 5. Again, it can be seen that the ANN model ranks first with $P_{50}=1.05$ and $P_{90}=1.62$, which means that, according to the third criterion, the ANN method tends to overpredict the measured pullout capacity by an average of $5 \%$. On the other hand, the LCPC method ranks last with $P_{50}=0.60$ and $P_{90}=1.50$, which suggests that, according to the third criterion, the LCPC method tends to underpredict the measured pullout capacity by an average of $40 \%$. It can also be seen that three of the remaining methods (i.e., Aoki and De Alencar, Penpile, and Schmertmann) tend to underpredict the measured pullout capacity by average values of $34 \%, 31 \%$, and $27 \%$, respectively, whereas the methods of De Ruiter and Beringen and Tumay and Fakhroo tend to overpredict the measured pullout capacity by average values of $36 \%$ and $14 \%$, respectively. 
Fig. 5. Histogram and logarithm-normal distributions of $Q_{\mathrm{p}} / Q_{\mathrm{u}}$ of the pullout capacity prediction methods used: (a) Aoki and De Alencar (1975), (b) Penpile (Clisby et al. 1978), (c) Schmertmann (1978), (d) De Ruiter and Beringen (1979), (e) LCPC (Bustamante and Gianeselli 1982), ( $f$ ) Tumay and Fakhroo (1982), and ( $g$ ) ANN.
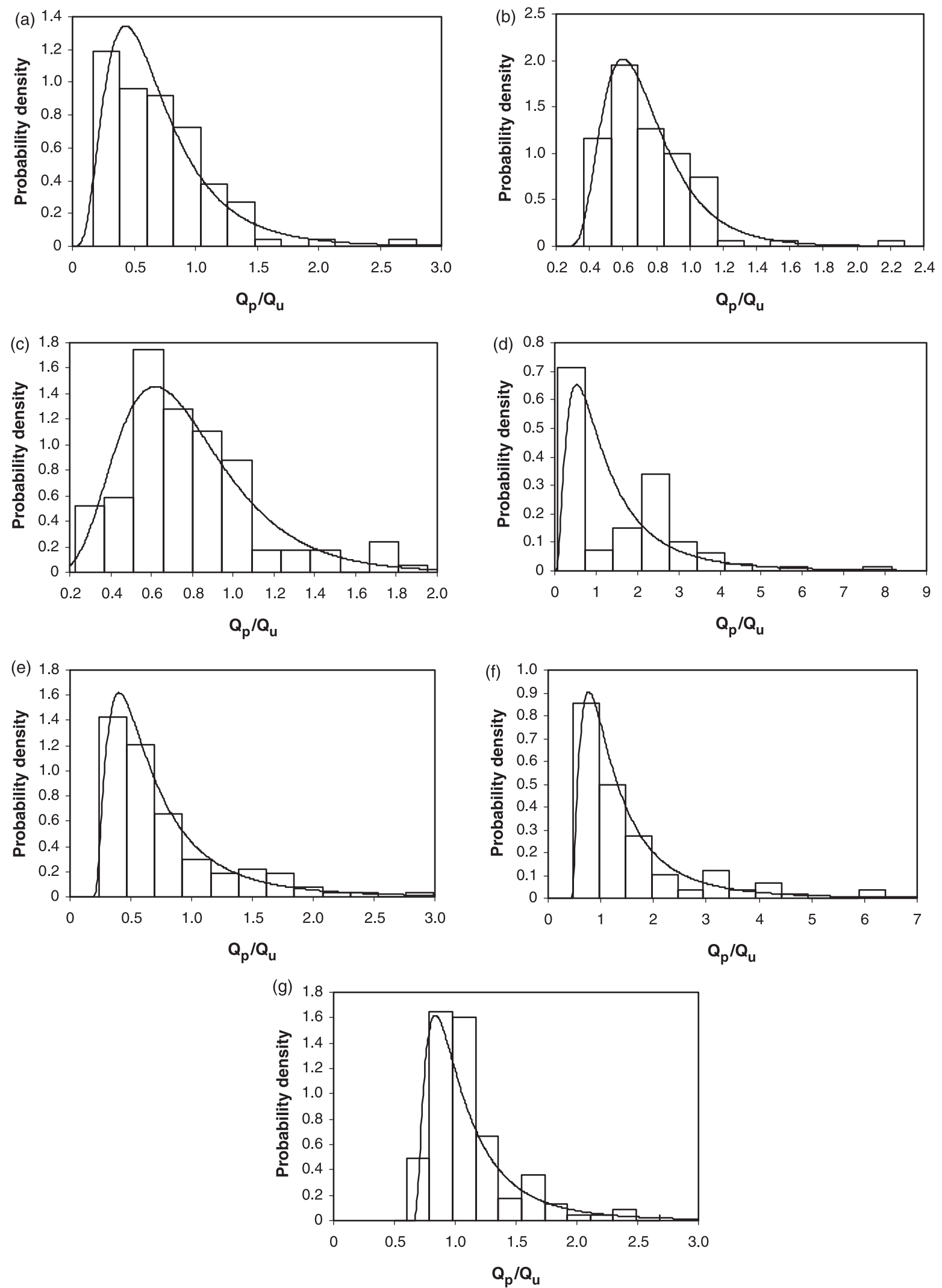
The fourth criterion $\left(R_{4}\right)$ is determined by plotting the histogram and logarithm-normal distributions of the ratio of $Q_{\mathrm{p}} / Q_{\mathrm{u}}$ of the 119 anchor tests for each of the pullout capacity prediction methods used. The probability of predicting the pullout capacity within $\pm 20 \%$ accuracy is then obtained by calculating the area beneath the logarithm-normal distributions within $0.8 Q_{\mathrm{u}} \leq Q_{\mathrm{p}} \leq 1.2 Q_{\mathrm{u}}$. Based on this criterion, the higher the probability of $\pm 20 \%$ accuracy, the better the performance of the prediction method. The histogram and logarithm-normal distributions of the methods used are shown in Fig. 5, and the corresponding probabilities and rank of the $\pm 20 \%$ accuracy are given in Table 5 . It can be seen from Table 5 that the ANN model is again ranked first for this criterion, with the highest logarithm-normal distribution and histogram probability values of $54.2 \%$ and $62.2 \%$, respectively. On the other hand, the LCPC method ranks last, with the lowest logarithm-normal distribution and histogram probability values of $18.1 \%$ and $12.6 \%$, respectively.

The results of the overall rank, RI, of the pullout capacity prediction methods used in this work are shown in Table 5. It can be seen that, according to the evaluation criteria used in this work, the ANN model of Shahin and Jaksa (2005) performs the best, followed by the method of Schmertmann (1978). The results also show that the method of De Ruiter and Beringen (1979) performs the worst.

\section{Summary and conclusions}

This paper studies the behavior of small ground anchors in various soil types by analyzing the results of a series of 119 in situ anchor pullout tests. The paper also examines and compares the performance of six cone penetration test (CPT) based methods and an artificial neural network (ANN) model recently developed by Shahin and Jaksa (2005) for pullout capacity prediction of ground anchors. In summary, and as expected, the measured pullout capacities were greater for soils of higher skin friction, as the width or diameter of the anchor increased, as the embedment depth of the anchor increased, and for static rather than dynamic installation. In addition, variability in the field test results was observed when replicate tests were performed. This was due to the natural spatial variability of the soil parameters and the inevitable minor variations in the installation and testing process. For the tests selected at the clayey and sandy sites, the maximum variability observed was $5 \%$ and $12 \%$, respectively.

The performance of the CPT methods chosen and the ANN model for pile capacity prediction was investigated using the rank index (RI), which compares the actual measured pullout capacity, $Q_{\mathrm{u}}$, with the corresponding predicted pullout capacity, $Q_{\mathrm{p}}$, from the prediction methods used. The rank index used comprises four statistical criteria including the best-fit line of $Q_{\mathrm{p}}$ versus $Q_{\mathrm{u}}$, the arithmetic mean and standard deviation of $Q_{\mathrm{p}} / Q_{\mathrm{u}}$, the $50 \%$ and $90 \%$ cumulative probability of $Q_{\mathrm{p}} / Q_{\mathrm{u}}$, and the $\pm 20 \%$ accuracy of the histogram and logarithm-normal distribution curves of $Q_{\mathrm{p}} / Q_{\mathrm{u}}$.

The results of the rank index used as a basis for comparison of the pile pullout capacity prediction methods yielded the following overall rank: 1, the ANN model (Shahin and Jaksa 2005); 2, Schmertmann (1978); 3, Tumay and Fakhroo (1982); 4, Penpile (Clisby et al. 1978); 5, Aoki and
De Alencar (1975); 6, LCPC (Bustamante and Gianeselli 1982); 7, De Ruiter and Beringen (1979). The results also indicate that, in general, the Aoki and De Alencar, Penpile, Schmertmann, and LCPC methods tend to underpredict the measured pullout capacity, whereas the ANN, De Ruiter and Beringen, and Tumay and Fakhroo methods tend to overpredict the measured pullout capacity.

\section{Acknowledgements}

The fieldwork and testing detailed in this paper were undertaken in 1999 and 2000 as part of final-year research projects carried out by T.L. Hampton, B.T. Scott, G.T. Tuck, C.R. Willis, H.K. Chia, W.R. Chin, K.W. Gan, and L.P. Teh under the supervision of the second author. Practical and technical assistance from the instrumentation and laboratory staff of the School of Civil and Environmental Engineering, the University of Adelaide, Australia, was provided by the late Mr. Tadeusz Sawosko and Messrs. Ian Cates, Greg Atkins, David Hale, and Bruce Lucas, and their contribution is gratefully acknowledged. In addition, the authors wish to thank Robian Industries Pty. Ltd. for supplying the ground anchors used for testing.

\section{References}

Abu-Farsakh, M.Y., and Titi, H.H. 2004. Assessment of direct cone penetration test methods for predicting the ultimate capacity of friction driven piles. Journal of Geotechnical and Geoenvironmental Engineering, ASCE, 130(9): 935-944.

Aoki, N., and De Alencar, D. 1975. An approximate method to estimate the bearing capacity of piles. In Proceedings of the 5th Pan-American Conference of Soil Mechanics and Foundation Engineering, Buenos Aires, Argentina, 27-31 October 1975. Vol. 1, pp. 367-376.

Bustamante, M., and Gianeselli, L. 1982. Pile bearing capacity prediction by means of static penetrometer CPT. In Penetration Testing: Proceedings of the 2nd European Symposium on Penetration Testing, Amsterdam, The Netherlands, 24-27 May 1982. Edited by A. Verruijt, F.L. Beringen, and E.H. De Leeuw. A.A. Balkema, Rotterdam, The Netherlands. Vol. 2, pp. 493-500.

Clisby, M.B., Scholtes, R.M., Corey, M.W., Cole, H.A., Teng, P., and Webb, J.D. 1978. An evaluation of pile bearing capacities. Report Volume 1, Final Report, Mississippi State Highway Department, Jackson, Miss.

Das, B.M. 1990. Earth anchors. Developments in geotechnical engineering 50. Elsevier Science Publishers BV, Amsterdam, The Netherlands.

De Ruiter, J., and Beringen, F.L. 1979. Pile foundation for large North Sea structures. Marine Geotechnology, 3(3): 267-314.

Ghaly, A.M., and Clemence, S.P. 1998. Pullout performance of inclined helical screw anchors in sand. Journal of Geotechnical and Geoenvironmental Engineering, ASCE, 124(7): 617-627.

Hanna, T.H., Sparks, R., and Yilmaz, M. 1972. Anchor behavior in sand. Journal of the Soil Mechanics and Foundations Division, ASCE, 98(11): 1187-1200.

International Society of Soil Mechanics and Foundation Engineering. 1989. Appendix A: International reference test procedure for the cone penetration test (CPT). Report of the ISSMFE Technical Committee on Penetration Testing of Soils, TC-16, With Reference to Test Procedures: CPT-SPT-DP-WST, No. 7, pp. 6-16. 
Lau, D.S., and Simmons, J.V. 1986. Interpretation of field tests on small-scale ground anchors. In Specialty Geomechanics Symposium: Interpretation of Field Testing for Design Parameters, Adelaide, Australia, 18-19 August 1986. Institution of Engineers Australia, Barton, Australia. pp. 85-88.

Long, J.H., and Wysockey, M.H. 1999. Accuracy of methods for predicting axial capacity of deep foundations. In Analysis, Design, Construction, and Testing of Deep Foundations: Proceedings of the OTRC ' 99 Conference, Austin, Tex., 29-30 April 1999. Edited by J.M. Roesset. American Society of Civil Engineers (ASCE), Reston, Va. Vol. GSP No. 88, pp. 190-195.

Lun, P.T.W. 1985. A review of ground anchors in cohesionless soils. Technical Report 139, Division of Geomechanics, CSIRO, Mt. Waverley, Victoria, Australia. pp. 1-15.

Rumelhart, D.E., Hinton, G.E., and Williams, R.J. 1986. Learning internal representation by error propagation: Explorations in the microstructure of cognition. In Parallel distributed processing. Edited by D.E. Rumelhart, J.L. McClelland, and the PDP Research Group. MIT Press, Cambridge, Mass. Vol. 1, Chap. 8.
Schmertmann, J.H. 1978. Guidelines for cone penetration test, performance and design. Report FHWA-TS-78-209, US Department of Transportation, Washington, DC.

Shahin, M.A., and Jaksa, M.B. 2003. Modelling the pullout capacity of marquee ground anchors. Research Report 174, School of Civil and Environmental Engineering, The University of Adelaide, Adelaide, Australia.

Shahin, M.A., and Jaksa, M.B. 2005. Neural network prediction of pullout capacity of marquee ground anchors. Computers and Geotechnics, 32(3): 153-163.

South Australian Department of Mines and Energy. 1989. Soil association map of the Adelaide region. 2nd ed. South Australian Department of Mines and Energy, Adelaide, Australia.

Tumay, M.T., and Fakhroo, M. 1982. Friction pile capacity prediction in cohesive soils using electric quasi-static penetration tests. Interim Research Report 1, Louisiana Department of Transportation and Development, Baton Rouge, La.

Xanthakos, P.P. 1991. Ground anchors and anchored structures. John Wiley \& Sons, Inc., New York. 